\title{
Building global learning communities
}

\author{
Thomas Cochrane ${ }^{\mathrm{a} *}$, Ilona Buchem ${ }^{\mathrm{b}}$, Mar Camacho $^{\mathrm{c}}$, Catherine Cronin ${ }^{\mathrm{d}}$, \\ Averill Gordon ${ }^{\mathrm{e}}$ and Helen Keegan ${ }^{\mathrm{f}}$
}

${ }^{a}$ Centre for Learning and Teaching, AUT University, Auckland, New Zealand; ${ }^{b}$ Department of Economics and Social Sciences, Beuth University, Berlin, Germany; ${ }^{c}$ Departament de Pedagogia, Universitat Rovira i Virgili, Catalunya, Spain; ${ }^{d}$ Department of Information Technology, National University of Ireland, Galway, Ireland; ${ }^{e}$ Department of Communications, AUT University, Auckland, New Zealand; ${ }^{f}$ Acoustics, Digital Media and Audio Engineering, Salford University, Manchester, UK

\begin{abstract}
Within the background where education is increasingly driven by the economies of scale and research funding, we propose an alternative online open and connected framework (OOC) for building global learning communities using mobile social media. We critique a three year action research case study involving building collaborative global learning communities around a community of practice of learning researchers and practitioners. The results include the development of a framework for utilising mobile social media to support collaborative curriculum development across international boundaries. We conclude that this framework is potentially transferrable to a range of educational contexts where the focus is upon student-generated mobile social media projects.
\end{abstract}

Keywords: community of practice; mlearning; global collaboration framework

\section{Introduction}

One of the key graduate attributes that lecturers aspire to develop in their students is the ability to work collaboratively in teams to design creative solutions to real-world problems (Hager and Holland 2006). However the default mode of teaching in higher education has long been the development and delivery of a series of lectures delivered by a single lecturer. As lecturers we often fail to model collaboration and creativity in our teaching practice. Laurillard (2012) argues that "a 21 st century education system needs teachers who work collaboratively to design effective and innovative teaching, and digital technologies are the key to making that work" (Laurillard 2012, p. 1). Balsamo (2011) argues that an "epistemological reboot" is required to transform universities by treating technology as a post-disciplinary topic, going beyond the traditional bounds of instructional design practices and engaging in connectivist pedagogies. Reeves (2005), and more recently Gunn (2011), call for new approaches to collaborative educational technology research and practice that move beyond the bounds of fixed-term government funded research projects focusing upon comparative analysis of educational technologies, with limited pedagogical transformation, that cease to exist after the funding runs out. In the unfunded realm, there are many

*Corresponding author. Email: thomas.cochrane@aut.ac.nz

RLT 2013. (C) 2013 T. Cochrane et al. Research in Learning Technology is the journal of the Association for Learning Technology (ALT), a UK-based professional and scholarly society and membership organisation. ALT is registered charity number 1063519. http://www.alt.ac.uk/. This is an Open Access article distributed under the terms of the Creative Commons Attribution 3.0 Unported (CC BY 3.0) Licence (http://creativecommons.org/licenses/by/3.0/) permitting use, reuse, distribution and transmission, and reproduction in any medium, provided the original work is properly cited. 


\section{T. Cochrane et al.}

special interest groups of educators, but little evidence of the impact of these groups for sustained pedagogical change.

In response to this, the icollab mobile social media community of practice $(\mathrm{CoP})$ was born out of the common interests of a group of lecturers from four countries (New Zealand, UK, Spain, Germany), all interested in exploring collaborative pedagogical transformation enabled by mobile social media technologies in higher education. The CoP leveraged the success of several of the lecturers' prior mlearning projects (see for example http://ourmproject.wordpress.com), and the design of the subsequent mobile social media projects was informed by the researcher's experience of implementing social constructivist learning environments using mobile social media in over 40 projects (Cochrane 2012). The goal of the icollab CoP is:

To create paradigm shifts in the participants' conceptions of teaching and learning, and in the disciplines themselves, leading to student generated content and student generated contexts in learning (Keegan and Bell 2011; Luckin et al. 2010), which cross disciplinary boundaries through digital networks and new media technologies. (Cochrane and Keegan 2012)

Thus a group of like-minded lecturers were invited by the researcher to establish a CoP to explore and learn from each other's unique experience and expertise in pedagogical transformation, using these to inform their teaching practice. These included:

- International collaboration (Gordon 2011)

- Mobile student-generated media (Keegan and Bell 2011)

- Serendipitous learning (Buchem 2011)

- Heutagogical approaches to education facilitated by mlearning (Cochrane and Rhodes 2011)

- Designing mobile learning courses (Buchem and Camacho 2011)

Each of the lecturers initially chose one of their 2011 student classes to participate in implementing the icollab project, and the researcher participated as a technology steward within the lecturer $\mathrm{CoP}$ working alongside the New Zealand lecturers and their students. The icollab CoP continued in 2012 and 2013. Figure 1 illustrates the development of the icollab $\mathrm{CoP}$ and the relationship between the central lecturer $\mathrm{CoP}$ and the five course CoPs involved in the 2013 icollab project.

Table 1 provides a summary and comparison of the three iterations of the icollab CoP projects.

The research question driving the icollab $\mathrm{CoP}$ is:

- How can a global, virtual learning community utilise mobile social media to broker a redefinition of pedagogy around student co-creation across international boundaries enabling pedagogical transformation in multiple contexts?

\section{Theoretical Frameworks}

A common focus of mlearning research has been teacher-directed content delivery for small screen devices [for example Stead and Colley (2008)] enabling flexible self-paced learning, but not leveraging the potential of mobile devices for collaborative learning as recommended by Hoppe et al. (2003) and reiterated by more recent calls for reenvisioning the potential of mlearning (Belshaw 2010; Kukulska-Hulme 2010). 


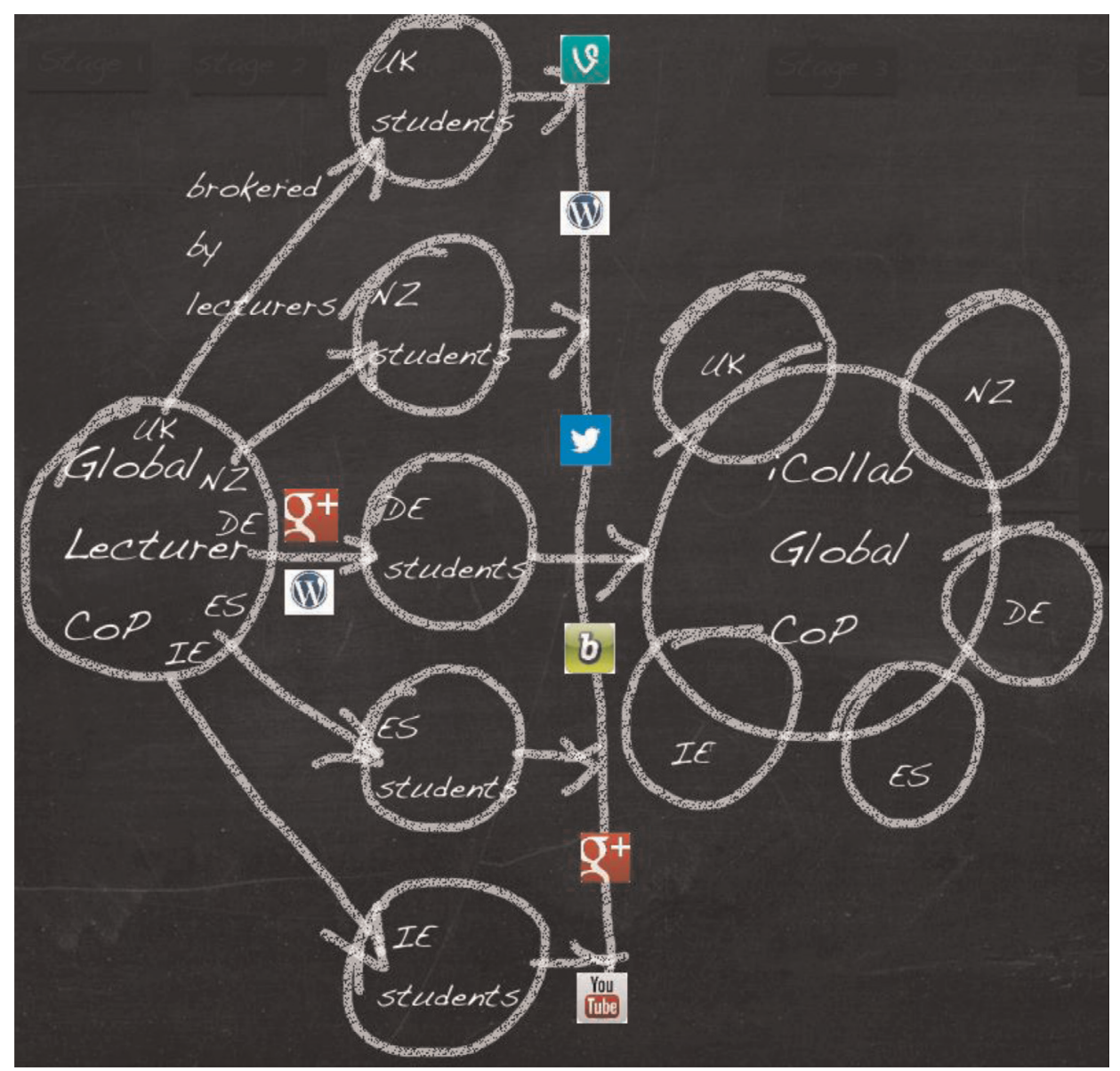

Figure 1. The development of the iCollab CoP.

A review of 102 mobile learning projects published between 2002 and 2007 (Frohberg, Goth, and Schwabe 2009) found that only 5\% of these projects focused upon social learning, with only $10 \%$ facilitating user-generated content. In comparison, the icollab project explicitly focuses upon leveraging the collaborative affordances of mobile social media based upon social constructivist learning theory (Vygotsky 1978) as its core foundation, and is informed by two key teaching and learning frameworks: Communities of Practice (Lave and Wenger 1991; Wenger 1998; Wenger, White, and Smith 2009) and Learner-Generated Contexts (Luckin et al. 2010).

According to theorists such as Vygotsky (1978), learning is a social process of student exploration guided by more experienced peers. Social constructivism forms a theoretical framework for collaborative learning frameworks such as pedagogy 2.0 (McLoughlin and Lee 2010) and communities of practice that are enabled by the use of social media (Wenger, White, and Smith 2009). This can be extended to the affordances of mobile social media as a catalyst for pedagogical change (KukulskaHulme 2010). CoP is a social learning theory (Lave and Wenger 1991; Wenger 1998; Wenger, White, and Smith 2009) that emphasises the process of membership in a community from initial peripheral participation to full participation as core members of the learning community. Brokering is another key concept of CoP theory. 


\section{T. Cochrane et al.}

Table 1. Comparison of three icollab project iterations.

\begin{tabular}{|c|c|c|c|}
\hline Year & 2011 & 2012 & 2013 \\
\hline Project title & icollab11 & icollab12 & icollab \\
\hline Project hub & Wikispaces & Wordpress & Wordpress \\
\hline \multirow[t]{4}{*}{ Participants } & $N=70$ students & $N=70$ students & $N=320$ students \\
\hline & $N=7$ lecturers & $N=5$ lecturers & $N=6$ lecturers \\
\hline & $N=5$ courses & $N=4$ courses & $N=5$ courses \\
\hline & $N=4$ countries & $N=4$ countries & $N=5$ countries \\
\hline \multirow[t]{2}{*}{ Mobile devices } & $\begin{array}{l}\text { iPhone } 4 \text { and iPad1 } \\
\text { (Unitec), and }\end{array}$ & Student-owned devices & $\begin{array}{l}\text { Student-owned } \\
\text { devices }\end{array}$ \\
\hline & Student-owned devices & & \\
\hline Pedagogy & Student-directed & Student-directed & Student-directed \\
\hline Project focus & $\begin{array}{l}\text { Virtual cultural } \\
\text { exchange }\end{array}$ & $\begin{array}{l}\text { Students as social } \\
\text { media reporters }\end{array}$ & $\begin{array}{l}\text { Students as social } \\
\text { media reporters }\end{array}$ \\
\hline \multirow{7}{*}{$\begin{array}{l}\text { Web } 2.0 \text { tools used } \\
\text { for collaboration }\end{array}$} & Wikispaces & Wordpress & Wordpress \\
\hline & Twitter & Storify & Storify \\
\hline & Qik & Twitter & Twitter \\
\hline & Skype & Qik & Scoopit \\
\hline & Polleverywhere & Facebook & Bambuser \\
\hline & & Google Plus & Vine \\
\hline & & Polleverywhere & $\begin{array}{l}\text { Google Plus } \\
\text { Polleverywhere }\end{array}$ \\
\hline $\begin{array}{l}\text { Example outputs: } \\
\text { selected student } \\
\text { projects }\end{array}$ & $\begin{array}{l}\text { http://www.youtube. } \\
\text { com/playlist?list= } \\
\text { PL546B03EE313199EF }\end{array}$ & $\begin{array}{l}\text { http://www.youtube. } \\
\text { com/playlist?list }= \\
\text { PL4C72B10F1B2AC723 }\end{array}$ & $\begin{array}{l}\text { http://www.scoop.it/ } \\
\text { t/ct231-student- } \\
\text { showcase }\end{array}$ \\
\hline Research outputs & $\begin{array}{l}\text { Buchem et al. (2012); } \\
\text { Buchem, Keegan, and } \\
\text { Camacho (2012); } \\
\text { Cochrane et al. (2011) }\end{array}$ & $\begin{array}{l}\text { Cochrane et al. } \\
(2012 \mathrm{a}) \text {; Cochrane } \\
\text { and Keegan (2012); } \\
\text { Cochrane et al. } \\
\text { (2012b) }\end{array}$ & In review \\
\hline
\end{tabular}

The reified activity of a CoP results in artefacts that can be used to broker the practice of the CoP across contextual boundaries. Brokering involves the transfer of an element of one practice into another across CoP boundaries, and an individual acting as a broker should be a member of both the CoPs between which they are brokering.

Learner-generated contexts provide a framework that redefines pedagogy from teacher-directed pedagogy to student-directed learning (Blaschke 2012; Hase and Kenyon 2000; Luckin et al. 2010). Within the context of the icollab CoP, we explore heutagogy (student-directed learning) as a framework for our students to experience authentic international collaboration within student-negotiated teams incorporating student-negotiated learning outcomes and assessment strategies, enabled by mobile social media tools. Thus, similarly to Puentedura's (2006) SAMR (Substitution, Augmentation, Modification, Redefinition) model, we focus upon redefining the use of mobile social media to achieve pedagogical transformation. The icollab CoP also resonates with Garnett and Ecclesfield's (2011) proposed framework for open scholarship that they describe as "participating in the perpetual beta of knowledge creation through the co-creation of learning" (Garnett and Ecclesfield 2011, p. 15).

\section{Methodology}

The icollab11 project explored distributed collaboration of a group of lecturers interested in the potential of mobile social media for transforming pedagogy. 
Mobile social media was used as an enabler and catalyst within the project (Buchem et al. 2012; Cochrane et al. 2011). The desire of the participants to generate positive change within their respective institutions, beginning with their own teaching practice, meant that the project was well suited to a participatory action research methodology (Swantz 2008). The project has involved several action research cycles thus far from 2011 to 2013, beginning with the initial establishment of an intentional $\mathrm{CoP}$ of the participating lecturers in early 2011, followed by concurrent yet disperse student-centred collaborative projects in the second half of 2011 through 2013. As a qualitative action research project, the authors are interested in sharing and critiquing the story of a journey of collaboration, student co-production, and pedagogical transformation. Thus the empirical data from the projects takes the form of the reified activity of the CoP such as student eportfolios, student projects and the co-designed course outlines on Google Docs and Wordpress. It is the narrative of this journey and our reflections on this narrative that form the domain of common interest that sustains this unfunded international CoP.

Each course group is framed around a local $\mathrm{CoP}$, and the reified activities of each course CoP, for example: YouTube videos recorded via smartphones, interaction via Twitter and SMS polling via http://polleverywhere.com. These were brokered between the groups by the lecturers in an attempt to use these boundary objects to bring the disperse student groups into an encompassing international CoP. Each group utilised participant-owned mobile devices focusing upon cross-platform (iOS, Android, Symbian, Windows Phone7-8) mobile social media services for communication and collaboration (e.g. YouTube, Twitter, Google Plus). Each of the student groups explored a variety of mobile social media tools relevant to their own course context and then created and shared a variety of student-generated projects. The goal was to create a virtual cultural exchange between the countries with each project highlighting a unique aspect of their own country and culture. The project began with the sharing of short 30 second YouTube introduction videos of each participant (http://tinyurl.com/cn4pspc) to establish a sense of relationship, and the creation of a group wiki (http://icollab11.wikispaces.com/). Next the student-generated mobile social media projects were collated on the group wiki page at http://icollab11. wikispaces.com/StudentPresentationLinks and then links to these projects were shared via Twitter using the \#icollab11 hashtag for rating, comment, critique and feedback between the groups. Thus we attempted to establish a virtual global community via a range of asynchronous mobile social media collaboration tools. Each group also undertook several class sessions where they screened and critiqued the shared projects. These projects included: creating layers of geotagged data for augmented reality browsers on unique architectural designs around Auckland City (Unitec Architecture student projects), eliciting student peer feedback via votes on Polleverywhere.com on attitudes towards the Rugby World Cup hosted in Auckland (AUT students), Prezi.com presentations exploring the benefits and pitfalls of mobile social media in post-communist Germany (Beuth University students), YouTube tutorials on how to maximise the impact of mobile social media (Salford students), and a Facebook group exploring the ethics of mobile social media in education (Tarragona students).

Because the project involved the interaction of several different courses from several institutions around the world, social media tools were utilised for collaboration rather than any of the institutions hosted Learning Management Systems (LMS). The use of social media provided an institutionally independent platform for 


\section{T. Cochrane et al.}

collaboration. This approach also enabled a pedagogical shift from a focus upon teacher-controlled learning spaces to a focus upon a collection of student-owned social media spaces or eportfolios into which they then invited their lecturers and peers.

\section{Results}

Each course incorporated the icollab projects into their existing course structure with the student-generated projects framed around course content and outcomes and the scope of the projects negotiated between each lecturer and their own students. For example, the Universitat Rovira i Virgili participated in the \#icollab11 project by involving 20 second-year students of the School of Education, investigating the use of social mobile media for collaborative purposes. The inclusion of a module related to Mobile Learning contributed to a better understanding of the wide range of possibilities that these students may face as trainee teachers and the impact of mobile devices in classrooms, providing an authentic experience utilising the mobile devices that constitute a very relevant part of their daily life.

Each course also assessed the outcomes of the project within the framework of their own existing course structure. For example, within the 2011 AUT Public Relations course, the outcomes of the project were assessed through the degree of student participation, the standard of exam question responses and personal interviews with students. All the students started using Twitter more frequently and developed an increased understanding of its value in public relations. This suggested that there was an emergence from a peripheral to central participation in the CoP as they began by taking low-risk collaboration until they became more experienced (Lave and Wenger 1991). The AUT students were formally assessed by two exam questions. One was based on analysing and applying the content they had covered in class and associated readings. The second was based on the collaboration project. The students answered the latter question in a more analytic and thorough manner, illustrating an improved learning experience.

The icollab11 project established a framework and built up the trust within the lecturer international CoP. Informed by these experiences the icollab CoP continued in 2012 as reified by the icollab12 project curated at http://icollab12.wordpress.com. The icollab12 project built on the icollab11 experience exploring student-generated digital identity and social media reporting across New Zealand, UK, Spain and Germany (http://icollab12.wordpress.com/about/). The core of the icollab12 project was the continued $\mathrm{CoP}$ of lecturers across the four countries established in 2011 by the icollab11 project. As the lecturers reflected on the icollab11 virtual cultural exchange project, a new collaborative project was brainstormed for 2012 involving students as social media reporters. Thus as part of the icollab12 international project, students in each participating country were required to move beyond the "classroom" and use their skills in digital communications and social media content production to become transmedia reporters or citizen journalists within their own contexts. They were required to work in teams to develop a series of reports for (and in collaboration with) the icollab12 international audience. The main focus of the project was to produce rich media reports on Social Media in the context of (a) their local community, and (b) their chosen industry. Their reports were then presented to the other students in the UK, Germany, Spain and New Zealand. The presentations took a variety of formats including: synchronous mobile video 


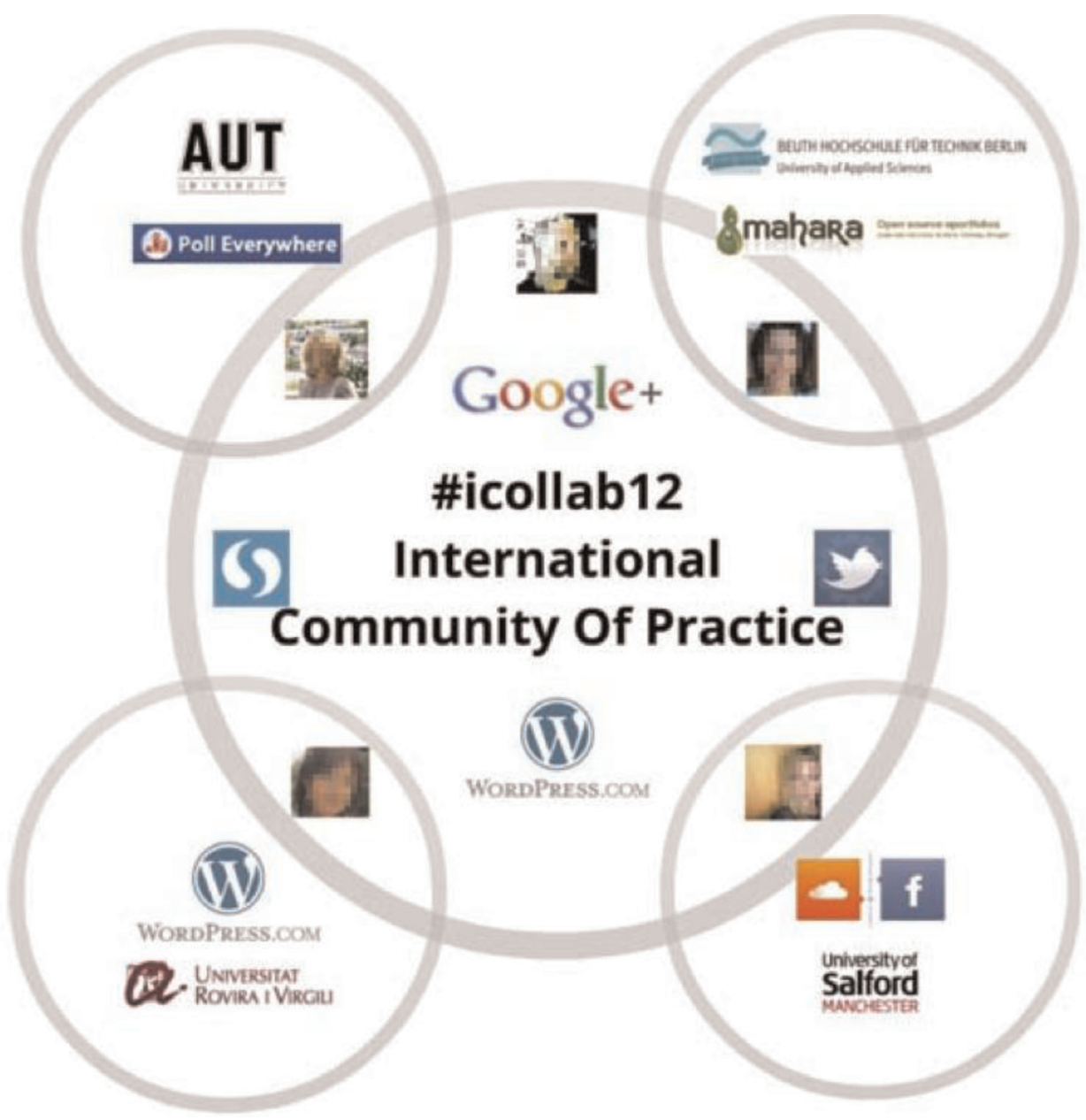

Figure 2. The icollab12 CoP.

streaming via Qik or Bambuser and live feedback via Twitter, pre-recorded YouTube videos, Slideshare or Wordpress. At the end of the project, students in each country were asked to vote for the best "Social Media" report (see http:// tinyurl.com/dyp9trp), and the winners received an iTunes voucher. Polleverywhere was used as a mobile voting system for the participants to vote for the best student social media reports. This project was further refined in 2013 and expanded with the addition of a group from Ireland and is curated at http://icollab.wordpress.com (Figure 2).

Feedback from students over the iterations of the icollab projects illustrates the transformative experience of participating in a global CoP: "I was exposed to a broad range of technologies including apps, hardware, and social networking and marketing tools. The course provides a good platform for enhancing an online presence, which is vital to creative professionals in a competitive market" (Student blog post 2011). "Thanks to this project I have transformed my understanding of social media usage, I understood how powerful it is and I enjoyed it a lot" (Student blog post 2012). 


\section{T. Cochrane et al.}

\section{Discussion}

The icollab $\mathrm{CoP}$ is an unfunded project, unconstrained by funding milestones, made up of a group of like-minded lecturers exploring the application of new learning paradigms enabled by mobile social media tools. Thus, it is an open-ended project that is envisioned to develop through several iterations as long as there are interested participants. Examples of other international mlearning CoPs include the LinkedIn Handheld Learning group (http://tinyurl.com/cyyahox), the mobile learning research Google group (http://tinyurl.com/d2hnpkt) and the International Association of Mobile Learning (http://www.iamlearn.org). However, these cover a much broader range of mlearning interests, require some form of membership and are not necessarily focused upon implementing international collaboration between lecturers or groups of students. Another current phenomenon is the MobiMOOC (De Waard 2012) or mobile MOOC. The icollab CoP is differentiated from MOOCs as the goal of the icollab $\mathrm{CoP}$ is to broker student collaboration and pedagogical transformation across global institutional contexts. In comparison, generally a cMOOC stands apart from institutions and an xMOOC arguably functions mainly as a feeder or marketing for an institution. By focusing upon Massive numbers, MOOCs lose what we argue is the all important focus upon building relationships that has been the sustaining characteristic of the icollab Cop, which could be called an OOC (Open Online Course, without being Massive). The linking of relatively small student cohorts internationally is in fact one of the strengths of the icollab CoP.

The icollab11 project began with the lecturers modelling international collaboration themselves as they formed an international $\mathrm{CoP}$ using a range of mobile social media collaboration and communication technologies while co-creating ideas for curriculum integration of these tools (Buchem et al. 2012; Cochrane et al. 2011). The researcher acted as an initial broker and technology steward for the group. The icollab11 lecturer CoP established a successful partnership among the seven participating lecturers. However, the lecturer $\mathrm{CoP}$ was largely invisible to the six student groups involved in the icollab11 project. While the icollab11 project established the lecturer $\mathrm{CoP}$ and a framework for collaborative technical and pedagogical support, the icollab12 project illustrated a move towards a heutagogical approach with the mobile social media projects becoming essentially student-driven. For several of the student groups, the icollab12 project was a non-assessed project that added an authentic collaborative experience to their course, but did not contribute to their summative assessment. The level of student engagement in this non-assessed project was beyond the expectations of the lecturers. What was powerfully motivating for the students was the opportunity for participation within an authentic international collaborative experience, brokered and modelled by their lecturers.

More explicit brokering of the lecturer CoP into the student CoPs was explored in the 2012 iteration of the project as this facilitated: (1) modeling of CoP participation and the use of mobile social media tools for communication and collaboration across international boundaries, (2) establishing a sense of international lecturer participation via mobile social media within the student CoPs bringing their unique experience and expertise to enrich these disperse learning communities, and (3) more explicitly scaffolding the move from teacher-directed pedagogy to student-directed heutagogy (Luckin et al. 2010). 
The icollab CoP at its core is devoted to putting social constructivist theory to practise (Vygotsky 1978). This has been supported by following the heutagogical principles of student self-direction and the application of mobile social media, such as storytelling with social media, blogging and microblogging including embedding multimedia artefacts as boundary objects (such as student-generated videos) or documenting and reflecting shared learning experience in ePortfolios. However, striking a balance that scaffolds guided student-generated enquiry was found to be critical. Another issue involved reimagining the transposition of the academic calendar between the northern and southern hemispheres as an asset rather than an un-surmountable hurdle leading to creative collaborative curriculum design solutions.

We're now looking at the 'tag-team model' of education: the projects never end, as there is always a cohort to carry on, and lead into the next group, and when they overlap that's great - that's where the genuine collaboration happens. ... Traditionally, we deliver modules/courses, neatly chunked into 12 weeks, with units of assessment, leading to grades etc. and that's the way things are (generally) done. I'm not saying scrap all of that, but I do think that modules are best served as springboards to other things. Increasingly, students are connecting across levels and cohorts through Twitter and now we have exstudents getting together with current students, undergrads coming to postgrad classes (and vice versa) as they've connected online and have a genuine interest in getting involved in other groups/further curricula outside of their taught modules. (icollab lecturer 2012)

The icollab CoP continues to grow as like-minded lecturers hear about the project and join the core group. The latest member aptly summarises the icollab CoP ethos in a blog post:

We're very excited to be taking part in \#icollab this year. Students and lecturers across 5 countries will collaborate in a community of practice crossing disciplines and levels. Over recent years I've learned that moving away from the rigid boundaries of modules, timetables and term times can be a powerful way to unleash creativity and meaningful collaboration. This is what \#icollab is all about. (icollab lecturer 2013)

\section{Developing a framework for building global learning communities}

The icollab CoP illustrates an open, online and connected approach to building global learning communities (OOC). The framework of a lecturer CoP has been fundamental for providing support in terms of shared resources, best practice, authentic learning experiences, problem-solving strategies and for developing curriculum integration of collaborative student-directed projects. The icollab CoP has also been crucial for brokering these ideas across global boundaries. Through participation in the icollab CoP, the members have stimulated each other with their ideas on how to design different activities for students, which tools to use and how, how to support dispersed communication, and how to overcome other specific barriers such as privacy concerns. As a CoP, it has been a joint enterprise, which has been continually renegotiated by the members. Thus we argue that an international lecturer CoP provides the social context for developing a global learning community by giving structure and meaning, creating solutions and brainstorming new scenarios. An international lecturer $\mathrm{CoP}$ can result in developing practice, engagement in joint activities, development of interpersonal relationships and the creation 


\section{T. Cochrane et al.}

of artefacts to broker collaboration between groups of learners around the globe at a level that is difficult to achieve otherwise. The icollab global collaboration framework has four stages, utilising mobile social media for scaffolding and sustaining interaction in a global $\mathrm{CoP}$ across all four stages:

- Stage 1: Establishing a core CoP

- Establish regular lecturer CoP collaboration channels utilising a core suite of mobile social media tools, such as Google Plus and Twitter.

- Develop explicit collaboration goals via a shared wiki, Google Doc or group blog.

- Design for change: explore the affordances of mobile social media for supporting a redefinition of pedagogy around student-generated content and contexts.

- Stage 2: Brokering participation

- Lecturers broker the project and participation within a global $\mathrm{CoP}$ to their student cohorts.

- Stage 3: Nurturing participation

- Explicitly model participation within a CoP by inviting student team representatives to take part in the organising $\mathrm{CoP}$ via a $\mathrm{G}+$ Hangout.

- Facilitate opportunities for putting a face to the participants. For example: Lecturers participate explicitly as remote experts in each other's classes, and students present and share their team project reports via synchronous and asynchronous mobile video streaming (e.g. Skype, G+ Hangouts, and Bambuser).

- Leverage mobile social media such as Twitter for student communication and Scoopit for curating and sharing student-generated content globally.

- Encourage students to develop their own research questions and create global teams to investigate and collaborate on these.

- Stage 4: Brokering Practice

- Utilise social media (e.g. Google Docs, Mendeley, Scoop.it) for collaborative reflective scholarship (including conference and journal publications) as outcomes of the CoP.

- Build on projects across consecutive years of a student cohort utilising mobile social media eportfolios, enabling measurement of pedagogical change and its impact on students' learning over time.

- Utilise the reified activity of the global CoP for brokering the concept to a wider audience of interested peripheral participants.

Figure 3 illustrates the four-stage framework mapped to the development of the icollab CoP.

The icollab CoP represents a serendipitous collaboration of like-minded mlearning researchers. The presented framework is based upon our experiences of what it takes to make this collaboration sustainable and effective. However, we believe that this framework is potentially transferable to other contexts and allows creative freedom for other groups of educational researchers who share a common vision 


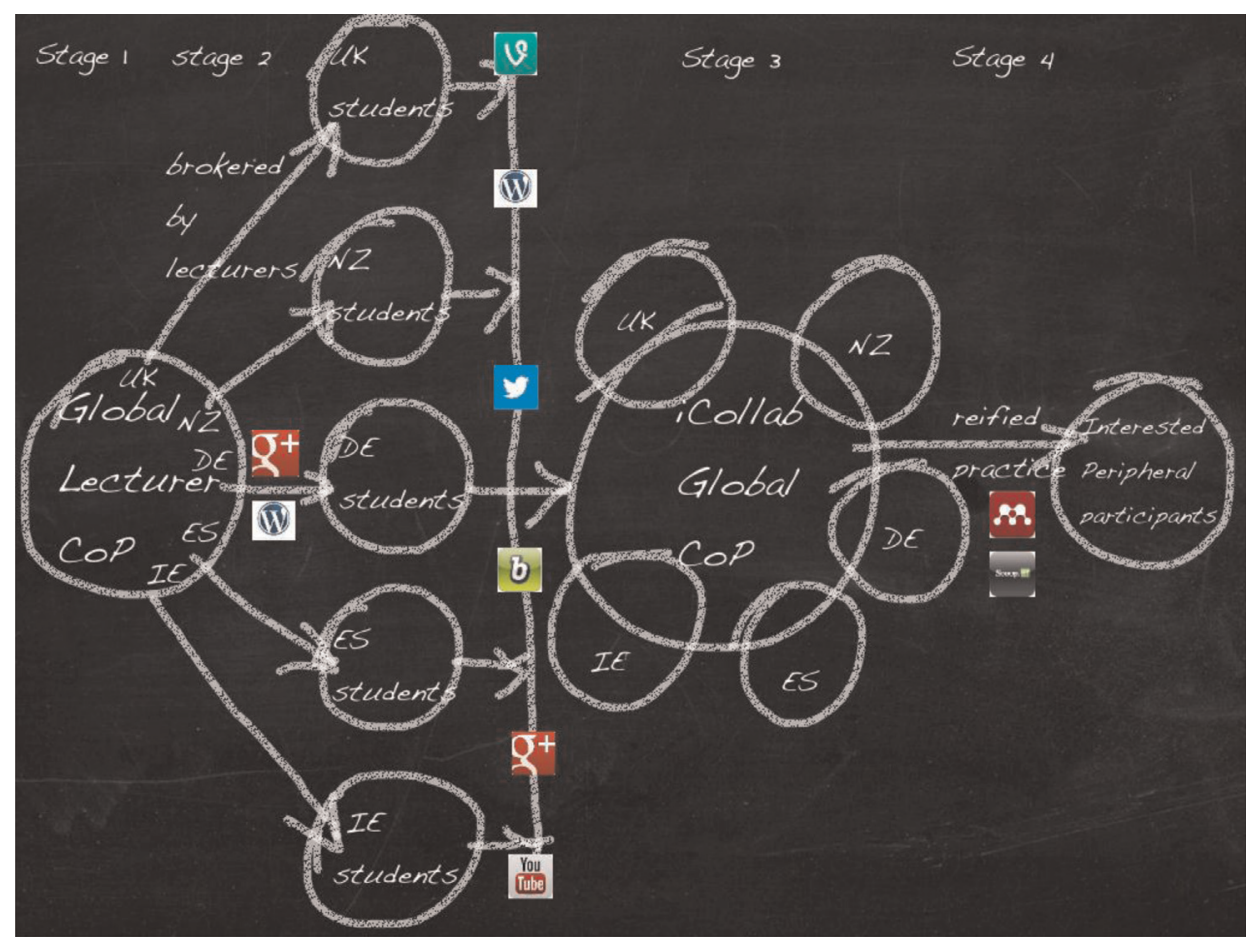

Figure 3. The four stages of the iCollab CoP framework.

to collaboratively explore and share that vision within a global context enabled by mobile social media.

\section{Conclusions}

The establishment of a sustained international lecturer $\mathrm{CoP}$ exploring mobile social media has led to a co-creative approach to the curriculum of the various courses participating in the icollab project. The activity of the icollab $\mathrm{CoP}$ is reified in the implementation of a rich variety of mobile social media tools providing a catalyst for new pedagogical strategies focusing upon student-generated content and student-generated contexts. The lecturer $\mathrm{CoP}$ was guided by the input of an educational technology researcher, and we argue that this model of sustained collaborative educational technology research is similar to that called for by Reeves (2005) and Laurillard (2012) to effect significant change in pedagogical outcomes. Brokering these CoPs across international boundaries was possible via a mix of asynchronous and synchronous mobile social media technologies enabling the brokering of an international community, with Twitter, Google Plus, moblogging, Google Docs and YouTube proving particularly effective. The transposed academic calendars between the northern and southern hemispheres proved difficult, but not un-surmountable, via planned timetabling of key course dates and a continuous tag-team approach. The icollab $\mathrm{CoP}$ continues to evolve, providing a potentially sustainable model that represents an epistemological reboot (Balsamo 2011) for 
building global collaborative learning communities reified in student-generated mobile social media projects.

\section{References}

Balsamo, A. (2011) Designing Culture: The Technological Imagination at Work, Duke University Press, Durham.

Belshaw, D. (2010) Mobile and Wireless Technologies Review, JISC infoNet, Newcastle upon Tyne, UK.

Blaschke, L. M. (2012) 'Heutagogy and lifelong learning: a review of heutagogical practice and self-determined learning', The International Review of Research in Open and Distance Learning, vol. 13 , pp. 56-71.

Buchem, I., et al. (2012) 'Mlearning 2.0: the potential and challenges of collaborative mobile learning in participatory curriculum development in higher education', Proceedings of the IADIS International Conference on Mobile Learning 2012, eds I. A. Sánchez \& P. Isaias, IADIS International Association for Development of the Information Society, Berlin, pp. 311-314.

Buchem, I. (2011) 'Serendipitous learning: recognizing and fostering the potential of microblogging',Form@re, vol. 2011,pp.3.

Buchem, I. \& Camacho, M. (2011) 'M-project: first steps to applying action research in designing a mobile learning course in higher education', in Mobile Learning: Crossing Boundaries in Convergent Environments, eds K. Rummler, J. Seipold, E. Lubcke, N. Pachler \& G. Attwell, London Mobile Learning Group, Bremen, pp. 123-135.

Buchem, I., Keegan, H. \& Camacho, M. (2012) 'Enhancing participatory culture: how to design international collaboration with social and mobile media?', Pre Conference Workshop, Online Educa Berlin 2012, Beuth University of Applied Sciences, Berlin, pp. 1-41, [online] Available at: http://www.slideshare.net/ibuchem/i-collab-oeb12preconfworkshop

Cochrane, T., et al. (2011) 'Mlearning 2.0: fostering international collaboration', ICERI2011: 4th International Conference of Education, Research and Innovations, eds I. Candel Torres, L. Gomez Chova \& A. Lopez Martinez, IATED, Madrid, Spain, pp. 42-51.

Cochrane, T., et al. (2012a) 'Global mobile social media reporters', Mobile Learning and Creativity Workshop (MLCW12) Held at the Seventh European Conference on Technology Enhanced Learning (EC-TEL 2012): 21st Century Learning For 21st Century Skills, eds I. Buchem, I. Jahnke \& C. Smith, Universitat Des Saarlandes, Saarbruecken, Germany, pp. 1-4, [online] Available at: http://cloudworks.ac.uk/cloud/view/6485

Cochrane, T., et al. (2012b) 'Post web 2.0 pedagogy: mobile social media', in Ascilite 2012: Future Challenges, Sustainable Futures, eds M. Brown, M. Hartnett \& T. Stewart, Wellington, New Zealand, ascilite, p. 63.

Cochrane, T. (2012) 'Critical success factors for transforming pedagogy with mobile Web 2.0', British Journal of Educational Technology, pp. 1-18, [online] Available at: http://dx.doi. org/10.1111/j.1467-8535.2012.01384.x

Cochrane, T. \& Keegan, H. (2012) 'New global learning cultures: interdisciplinarity through networked technologies', Selected Papers of Internet Research, vol. 0, pp. 1-31.

Cochrane, T. \& Rhodes, D. (2011) 'iArchi[tech]ture: heutagogical approaches to education facilitated by mlearning integration', Proceedings of the International Conference on Information and Communication Technologies in Education ICICTE 2011, eds K. Fernstrom \& C. Tsolakidis, University of the Fraser Valley and the University of the Aegean, Rhodes, Greece, pp. 112-121.

De Waard, I. (2012) 'Investigating learner interactions via ubiquitous access', in Mlearn 2012: The 11th World Conference on Mobile and Contextual Learning, eds M. Specht, J. Multisilta \& M. Sharples, IAmLearn, Helsinki, Finland, pp. 220-223.

Frohberg, D., Goth, C. \& Schwabe, G. (2009) 'Mobile learning projects - a critical analysis of the state of the art', Journal of Computer Assisted Learning, vol. 25, pp. 307-331.

Garnett, F. \& Ecclesfield, N. (2011) 'Towards a framework for co-creating open scholarship', in Proceedings of ALT-C 2011 - Thriving in a Colder and More Challenging Climate: The 18th International Conference of the Association for Learning Technology, eds D. Hawkridge, K. $\mathrm{Ng} \& \mathrm{~S}$. Verjans, Association for Learning Technology, University of Leeds, UK.

Gordon, A. (2011) Public Relations, Oxford University Press, Oxford. 
Gunn, C. (2011) 'Sustaining e-learning innovations', in Changing Demandseds, Changing Directions. Proceedings ascilite Hobart 2011, eds G. Williams, P. Statham, N. Brown \& B. Cleland, University of Tasmania, Hobart, Tasmania, Australia, pp. 509-519.

Hager, P. \& Holland, S., (eds) (2006) Graduate Attributes, Learning and Employability, Springer, Dordrecht, The Netherlands.

Hase, S. \& Kenyon, C. (2000) From Andragogy to Heutagogy. ultiBASE Articles, [online] Available at: http://ultibase.rmit.edu.au/Articles/dec00/hase2.htm

Hoppe, H. U., et al. (2003) 'Guest editorial: wireless and mobile technologies in education', Journal of Computer Assisted Learning, vol. 19, pp. 255-259.

Keegan, H. \& Bell, F. (2011) 'YouTube as a repository: the creative practice of students as producers of open educational resources'. European Journal of Open, Distance and E-Learning (EURODL), pp. 149-168, [online] Available at: http://www.eurodl.org/?p= special\&sp $=$ articles\&article $=456$

Kukulska-Hulme, A. (2010) 'Mobile learning as a catalyst for change', Open Learning: The Journal of Open and Distance Learning, vol. 25, pp. 181-185.

Laurillard, D. (2012) Teaching as a Design Science: Building Pedagogical Patterns for Learning and Technology, Routledge, New York.

Lave, J. \& Wenger, E. (1991) Situated Learning: Legitimate Peripheral Participation, Cambridge University Press, Cambridge.

Luckin, R., et al. (2010) 'Learner-generated contexts: a framework to support the effective use of technology for learning', in Web 2.0-Based E-Learning: Applying Social Informatics for Tertiary Teaching, eds M. Lee \& C. Mcloughlin, IGI Global, Hershey, PA.

Mcloughlin, C. \& Lee, M. (2010) 'Pedagogy 2.0: critical challenges and responses to web 2.0 and social software in tertiary teaching', in Web 2.0-Based E-Learning: Applying Social Informatics for Tertiary Teaching, eds M. Lee \& C. Mcloughlin, IGI Global, Hershey, PA.

Puentedura, R. (2006) 'Transformation, Technology, and Education', Hippasus, [online] Available at: http://hippasus.com/resources/tte/puentedura_tte.pdf

Reeves, T. (2005) 'No significant differences revisited: a historical perspective on the research informing contemporary online learning', in Online Learning: Personal Reflections on the Transformation of Education, ed G. Kearsley, Educational Technology Publications, Englewood Cliffs, NJ.

Stead, G. \& Colley, J. (2008) 'The power of me: learning by making your own rich media mobile resources'. in MLearn08: The Bridge from Text to Context, eds J. Traxler, B. Riordan \& C. Dennett, 7-10 October 2008, University of Wolverhampton, School of Computing and IT, Ironbridge Gorge, Shropshire, UK, 363.

Swantz, M. L. (2008) 'Participatory action research as practice', in The SAGE Handbook of Action Research: Participative Inquiry and Practice, eds P. Reason \& H. Bradbury, 2nd edn, SAGE, London.

Vygotsky, L. (1978) Mind in Society, Harvard University Press, Cambridge, MA.

Wenger, E. (1998) Communities of Practice: Learning, Meaning, and Identity, Cambridge University Press, Cambridge.

Wenger, E., White, N. \& Smith, J. (2009) Digital Habitats: Stewarding Technology for Communities, CPsquare, Portland, Oregon. 